\title{
Preparing for Practice: Parallel Processes of Identity Development in Stage 3 of Doctoral Education
}

\author{
Vicki L. Baker \\ Albion College, \\ Albion, MI, USA
}

vbaker@albion.edu

\author{
Meghan J. Pifer \\ Widener University, \\ Chester, PA, USA
}

mipifer@widener.edu

\begin{abstract}
As part of a longitudinal study, we examined Stage 3 of the doctoral student experience by further testing and refining the notion of a parallel process of identity development as student and scholar in doctoral education. We relied on a framework that integrates developmental networks and sociocultural learning to explore the types of learning and interactions students engage in to persist through Stage 3. Our results indicate that this identity development process is prompted by two program milestones in Stage 3: the dissertation and the search for employment. In comparing the experiences of students who pursued faculty appointments with those who pursued administrative careers, we found similarities and differences. We discuss these results and offer future directions of research and practice.
\end{abstract}

Keywords: Qualitative (why and how decisions are made), USA/Canada issue, business/commerce/organizational issue, people-focused issues, cross-disciplinary inquiry, dissertation issue, learners' characteristics, issue in preparing doctoral students, doctoral studies

\section{Introduction}

"The academic job market is the final gauntlet one has to survive." This quote from a student summarizes study participants' impressions of the final stage of the doctoral student experience, Stage 3, the time after the dissertation proposal defense that includes completion of the dissertation and the job search (Austin \& McDaniels, 2006; Gardner, 2008; Golde, 1998; Tinto, 1993). One component of the scholarship about doctoral education, the stage model, has been applied to understanding the doctoral student experience (Baker, Pifer, \& Flemion, 2013; Baker \& Pifer, 2011; Gardner, 2008; Grover, 2007, Lovitts, 2005, 2008). In the United States, Stage 1 includes the admissions process and the first year of courses. Researchers characterize this stage as being

Material published as part of this publication, either on-line or in print, is copyrighted by the Informing Science Institute. Permission to make digital or paper copy of part or all of these works for personal or classroom use is granted without fee provided that the copies are not made or distributed for profit or commercial advantage AND that copies 1) bear this notice in full and 2) give the full citation on the first page. It is permissible to abstract these works so long as credit is given. To copy in all other cases or to republish or to post on a server or to redistribute to lists requires specific permission and payment of a fee. Contact Publisher@,InformingScience.org to request redistribution permission. about knowledge consumption (Austin, 2002), given that students gain knowledge through formal instructional delivery and course work. In Stage 2, students often complete coursework, earn candidacy, and pass the dissertation proposal defense. Stage 2 has been characterized as a time of knowledge creation (Gardner, 2008; Lovitts, 2005, 2008). During this stage, students use the acquired skills from Stage 1 to create 
new knowledge that contributes to their respective fields of study through the commencement of original research, a process that begins through the development and defense of the dissertation proposal. In this paper, we offer a descriptor to characterize Stage 3: knowledge enactment. Based on findings from a qualitative study of Stage 3 that was part of a larger longitudinal study of doctoral education, we suggest that in this stage, students enact the technical and cultural knowledge they have acquired to effectively assume the role of the scholar by successfully defending a dissertation, entering the job market, and obtaining employment. This designator, knowledge enactment, captures the dynamic nature of the learning and identity changes that occur during this important, yet under-studied, stage of the doctoral student experience.

Elsewhere, we identified a parallel process of identity development during Stage 2 of doctoral education, during which students cultivate and enact their roles as both students and emergent scholars (Baker, Pifer, \& Flemion, 2013). Prior research has suggested that individuals experience identity shifts as a result of educational experiences (Anderson, Cutright, \& Anderson, 2013; Baxter Magolda, 2001; Chickering \& Reisser, 1993; Jazvac-Martek, 2009). While all three stages present challenges and require students to develop and adapt their approaches to learning, Stage 3 necessitates the management of that parallel identity process in a new way, altering students' approaches to learning as they move towards active engagement in community practices and seek legitimacy.

Existing literature has offered little knowledge of students' experiences during Stage 3 or the parallel process of identity development as students and scholars. Stage 3 is important to study, given the resources that have been invested in students' training to that point and its proximity to the goal of persistence to degree completion and becoming an independent scholar. There is a need for greater knowledge of this stage, and particularly students' evolving identities and the ways in which they develop as learners in relation to program milestones, their engagement in the practices of the academic community, and key relationships and interactions. The goal of this study was to better understand the parallel process of identity development during Stage 3 and how it affects knowledge enactment as a response to managing the challenges of the dissertation and the job market. The research questions that guided this analysis were

1) What program structures or milestones trigger identity development during Stage 3 of doctoral education, and in what ways?

2) In what ways do doctoral students perceive and manage the challenges of Stage 3 of doctoral education?

\section{Theoretical Framework}

To date, research has produced a general description of Stage 3 of doctoral education as it typically occurs in the United States (Barnes, 2007; Caplow \& McGee, 1958/2001; Hargens, 2011). The literature about Stage 3 points to two major milestones: the dissertation (Austin, 2002) and the job search (Austin \& McDaniels, 2006; Gardner, 2008; Golde, 1998; Golde \& Dore, 2001; Tinto, 1993). We review the literature about each of these milestones before presenting the two theoretical perspectives that inform our investigation, which are the parallel processes of identity development and networked sociocultural learning in doctoral education.

\section{Stage 3 Milestone: The Dissertation}

The dissertation is often the final program milestone associated with the doctoral student experience. According to the Council of Graduate Schools (CGS, 1990), the dissertation fulfills two major purposes. It serves as a training experience that illustrates one's ability to independently address important problems in a disciplinary domain, and it enables a student to make an original contribution to the field of interest. Authors including Roberts (2010) and Krathwohl and Smith 
(2005) have offered advice on how to manage the task through suggestions such as developing writing schedules, crafting and honing research ideas, and working with committee members.

Both academic supervisors and doctoral students have reported mixed emotions about the dissertation - more specifically, the usefulness of the traditional dissertation structure in preparing students for conducting independent research as well as for diverse career opportunities. Isaac, Quinlan, and Walker (1992) noted that faculty at doctoral-granting institutions view the dissertation as an essential part of a PhD program; however, some faculty members, policy-makers, and students have suggested alternatives to the dissertation or at least the need for a critical examination of this component of doctoral education and training (Geiger, 1997; Lipschutz, 2006; Pearson, 1999). Some current dissertation approaches in fields such as marketing, finance, and the sciences require students to write a series of research papers, an approach that is more similar to the scholarly writing and publication process (Baker Sweitzer, 2007). In a study conducted by Golde and Dore (2001), students reported being ill prepared for all aspects of research. Specifically, students indicated that the dissertation experience did not prepare them to publish or to conduct and supervise research projects.

Despite the questions surrounding the structure and purpose of the dissertation, there seems to remain an expectation that the dissertation is an opportunity, and a requirement, for students to engage in independent research and contribute to the body of knowledge in their respective fields of study. To successfully pass this milestone, students must begin to shed the student role, which implies reliance on others, and assume the role of scholar, one who can enact the knowledge obtained in prior stages to generate an original contribution to his or her field.

\section{Stage 3 Milestone: The Job Search}

In 2002, Austin identified completing graduate school as the first stage of the academic career, after which one must also successfully complete the academic job search. Research to date has included disciplinary perspectives on what constitutes an ideal job candidate (Anastas, 2006; Applegate, Cable, \& Sitren, 2009), socialization into the academy (Weidman, Twale, \& Stein, 2001), and students' sense of uncertainty surrounding the job search experience (Gardner, 2007; Yerkes, van de Schoot, \& Sonneveld, 2012). Little research has explored students' identity changes as they navigate the road to full-time employment in the academy. We also know very little about the experiences of doctoral students who do not intend to pursue academic careers upon degree completion.

Market trend studies have provided some insight into the job search (Hargens, 2011; Smeets, Warzynski, \& Coupé, 2006), such as the kinds of academic positions available, post-graduation placement figures, and the increase of part-time and contingent faculty at colleges and universities across the United States. In many graduate programs and disciplines, as well as in the research literature, there seems to be an assumption that doctoral students are in search of faculty careers. Golde and Dore (2001) revealed that this is not always the case, especially among disciplines that have close industry ties such as those in the Science, Technology, Engineering, and Mathematics (STEM) fields.

Recently, practitioners have offered guidance to help students navigate the academic job search, given the lack of guidance and deliberate developmental support that some students experience. While Lehker and Furlong (2006) noted that "on completion of their programs, graduate and professional students are assumed to have taken on a professional identity that is appropriate to their desired career outcomes" (p. 74), there is no evidence that such assumptions are accurate. Furthermore, scholars have not examined the transition students undergo as they complete their doctoral studies and develop a professional identity linked to career goals. 
Regardless of students' career aspirations, they must be clear about their goals and enact the professional identity needed to earn their desired employment positions. This process requires them to leave behind an identity that has long been part of their sense of self - that of student and learner. The ability to be an effective learner is fundamental across all roles (student, scholar-in training, scholar) and stages. It is the one constant in the equation; however, learning must evolve as students move through the phases of knowledge consumption, knowledge creation, and knowledge enactment as they transition from student to scholar. Doctoral students will not always be students, but they will always be learners. In Stage 3, they are learning how to be scholars and testing these roles through the dissertation and job search experiences. Additionally, students must begin to enact and assume the professional identity of the intended career in order to be deemed credible. This process is facilitated through knowledge enactment, through which students seek legitimacy and membership in the scholarly community by engaging in practices and behaviors learned during their prior doctoral training, such as sole authorship in academic publications and job talks through which they present their scholarly agendas and research activity.

\section{Parallel Identity Development in Doctoral Education}

In 1968, Douglas Hall documented the transition from student to professor. Hall found that students began to feel like academics by experiencing important program milestones. Kiley (2009) and Jazvak-Martek (2009) report similar processes. Kiley examined rites of passage related to the doctoral experience, and noted that as students pass through these rites of passage, the ways in which they viewed themselves as learners evolved. Jazvak-Martek, relying on role theory, found that students oscillate between the student role and other roles associated with being an academic as they develop their professional identities. Building on our prior research, we explored the ways in which students evolve as a result of the learning that occurs through key experiences. We examined changes in identity development as study participants transitioned through each stage of doctoral education. We examined each of the three stages in an effort to better understand the whole doctoral experience. Each stage requires students to adapt their approaches to learning, which is facilitated through behavioral cues from others in their networks of relationships.

In the earlier phases of this longitudinal study, we examined the learning and identity development that occurs across the first two stages of doctoral education in order to identify the evolution of students' learning and behavioral-based strategies (Baker, Pifer, \& Flemion, 2013; Baker \& Pifer, 2011). We relied on a framework developed by Baker and Lattuca (2010) that draws on developmental network theory and a sociocultural perspective of learning to explore the connections between developmental networks, learning, and identity development. The integrative framework emphasizes how doctoral students learn as a result of interactions with members of their developmental networks as they seek to become fully engaged in the community and its corresponding practices. Through our use of that framework, we found the role of relationships to be crucial in Stage 2 of doctoral education. We also identified the parallel processes of identity development as both student and scholar-in-training during that stage (Baker, Pifer, \& Flemion, 2013). Here, we rely on parallel identity development process as a conceptual guide for researching identity development through knowledge enactment in Stage 3 of doctoral education.

The term parallel process describes the simultaneous and intersecting identity development as both student and scholar that occurs through doctoral education (Baker \& Pifer, 2011). The role of learner is present across all identities and stages throughout the doctoral experience, yet it evolves and develops as students engage in community practices and interact with community members. Students' scholarly identities evolve over time in order to reflect their evolving relationships to knowledge and professional practices. Their identities as students simultaneously evolve in response to the structures and challenges associated with each stage, which facilitates 
their progression towards becoming independent scholars. The role of the learner evolves as students adopt new ways of more fully engaging in their intended communities and advance towards independence. While they will shed their identities as students, it is in fact essential that they maintain their roles as learners if they are to assume the identity of scholar and professional. The dissertation and job search not only allow students to demonstrate their scholarly identity, but they help facilitate its development through interactions with members of their developmental networks.

We are particularly interested in the transition out of the student role and into the role of scholar during this stage of the doctoral education process, and how this transition is characterized by an emphasis on knowledge enactment. As students engage these roles, their learning, behavioral strategies and interactions, and engagement in community practices continue to evolve in response to program milestones and related challenges as they progress towards degree attainment.

\section{Methods}

\section{Research Design}

Our exploration of the final stage of doctoral education was part of a longitudinal examination of the doctoral student experience in two social science fields, Business and Higher Education, within one research university in the United States. The Higher Education students who participated in this research were introduced into the study during the second phase of data collection; Business students participated in all three stages of data collection. Given that our goal was to better understand students' experiences and the role of developmental relationships in those experiences, we employed qualitative methods (Merriam, 2002). Qualitative methods allow for a particularly salient methodological approach, given our intent to gain a deeper understanding of the connection among students' experiences, learning, and identity change within and across the stages of the doctoral student experience as we sought to develop new theory surrounding these concepts. We included perspectives from students engaged in Stage 3, as well as from students who recently completed Stage 3. We studied doctoral experiences in Business and Higher Education for two primary reasons: (1) convenience sampling (Miles \& Huberman, 1994) due to our own personal and professional experiences in these fields, which brought access and administrative support to recruit research participants, and (2) purposeful sampling (Patton, 2002), given our interest in comparing experiences in two professional programs in the social sciences. We selected a research university that had nationally ranked doctoral programs in these two fields. These two sampling approaches allowed us to gain access to research participants in fields in which we have experience while also allowing us to be deliberate in our selection of the fields of interest.

Following the Eisenhardt (1989) model, we treated each participant's experience as a mini-case embedded in the larger departmental and institutional context in an effort to better understand the dynamics in a single setting. Eisenhardt's approach is fitting given the theory-building nature of our research. Very little research has explored the connection among student experience, learning, and identity development in doctoral education, with even fewer exploring this process connected to the program milestones associated with Stage 3 of the doctoral student experience. This approach enabled us to conduct comparisons among participants within and across two disciplines in the social sciences.

\section{Research Setting}

Central University (pseudonym) is a top-rated research institution with nationally ranked colleges of business and education (U.S. News and World Report, 2012). The College of Business awards doctoral degrees in five disciplines: Accounting, Finance, Marketing, Management and Organiza- 
tion, and Supply Chain and Information Systems. The doctoral program typically enrolls between ten and twelve doctoral students yearly across the five disciplines. Students only attend on a full-time basis and receive full funding for five years, the typical time to degree in business. Doctoral student training is geared towards research-intensive faculty careers as students are expected to obtain tenure-track faculty positions in other top-rated business schools.

Central's Higher Education doctoral program supports two degree programs, the PhD and DEd. The program offers tracks for faculty appointments as well as non-faculty appointments in higher education fields including institutional administration, state and federal government, postsecondary organizations and associations, research institutes, and private foundations. (In this paper, we refer to the non-academic careers collectively as administrative careers.) The Higher Education Program enrolls between three and twelve students yearly and the majority of students receive funding through the Higher Education Program for at least a portion of their experience. Students not fully funded through the Higher Education Program secure assistantships in student affairs divisions, research centers, or administrative offices across the university. The typical time to degree is 4.5 years.

\section{Study Participants}

A total of 31 students ( $n=18$, Business; $n=13$, Higher Education) participated in this research study. Fourteen participants were female (45\%). One was African American (3\%), four were Asian (13\%), two were Indian (sub-continent) (6\%), one student was Latino (3\%), and one was Asian American (3\%). The remaining 22 participants were White (71\%). Six participants were international students (19\%). All students in the entering cohorts were invited to participate. Of the 31 students who participated in this longitudinal research, 28 ( $n=18$, Business; $n=10$, Higher Education) participated in the phase that focused on Stage 3, which includes the data presented in this paper. The average participant age was 33 and the average amount of prior professional experience was 5.5 years in Business and 4 years in Higher Education. Participants in Business held prior professional roles such as accountant, financial analyst, marketing manager, and project manager. The PhD and DEd students in Higher Education held positions in residence life, admissions, alumni affairs, and development, as well as employment outside of higher education. While all the business doctoral students were interested in earning faculty appointments, only three students in Higher Education were interested in pursuing faculty appointments, with the remaining seven students indicating an interest in obtaining nonacademic appointments after degree completion.

\section{Data Collection Procedures}

At its inception, this was a longitudinal study of two cohorts of doctoral students in Business; the goal was to study participants throughout their entire doctoral student experience. Data collection began in fall 2005 (Business cohort 1) with a second Business cohort added in fall 2006. One of the study authors invited the Higher Education students to participate in this research beginning at Stage 2 (fall 2008) as a comparison group, given both programs represent professional fields in the social sciences. In both programs, a new cohort of doctoral students was admitted each fall. Neither model included structural components of a cohort model such as predetermined curricula, cohort projects, or team meetings. The culture of both programs, however, was constructed around the cohort as a source of support and identity for students. It was common for students to establish their earliest professional and social connections with their cohort peers, to be oriented into their programs with them, to take many classes with them, and to prepare together for milestones such as comprehensive exams and writing projects. Examining the cohort experiences within and across disciplines provided insight into commonalities and differences of the doctoral students' development and identity evolution. Following appropriate protocol for human subjects 
research, students were informed that participation was voluntary and that the university's institutional review board had approved the study.

A semi-structured interview protocol guided the interviews and addressed six main areas: (1) key experiences, (2) challenges, (3) goals for performance/advancement, (4) key relationships, (5) types of support present/absent, and (6) personal and professional identity. The six main areas focused on the two main Stage 3 hurdles: the dissertation and the academic job search. All interviews were conducted face-to-face or via telephone, lasted approximately one hour, and were recorded then transcribed verbatim.

\section{Data Analysis Procedures}

In order to maintain consistency with the team-based methods approach identified by MacQueen, McLellan, Kay, and Milstein (1998) and the theory-building nature of our research (Eisenhardt, 1989), we relied on deductive and inductive analytic procedures. Each of the study authors developed deductive codes independently, guided by the study protocol and our prior research about the parallel identity development process. These codes were linked to the six main themes addressed in the semi-structured interview protocol (noted above) as a primary level of coding, followed by a secondary level of coding that focused on student experiences, learning, and identity change in relation to Stage 3 program milestones. To complement the deductive analytic approach, we also implemented an inductive and iterative data analysis strategy of constant comparison between data collection, data analysis, and the extant literature (Eisenhardt, 1989) as we developed theory. The use of interviews with students engaged in the phenomenon and those who recently completed the phenomenon was of particular importance for theory development, through the creation of mini-case studies that we compared for similarities and differences among students within and between the fields under investigation. The longitudinal nature of the study further supported our analytic approach and the implementation of deductive and inductive coding to establish trustworthiness of the data. To further ensure trustworthiness of the data, we completed random member checks of ideas and themes, and used ideas from prior interviews to confirm and further hone the developed themes. The authors coded transcripts independently to identify analytic codes prior to the next round of interviews, and worked collaboratively to identify emerging themes as additional data were added.

\section{Results}

As in Stage 2 (Baker, Pifer, \& Flemion, 2013), we identified a parallel process of identity development in Stage 3 of doctoral education. While we anticipated that participants would shed their identities as students as they took on the identity of the scholar, we found that both identities remained crucial; thus, the parallel process of identity development that we observed in Stage 2 continued through Stage 3. Further, it was critical that students' approaches to learning evolved at this stage. Both the dissertation and the job search required students to remain firmly grounded in their student identity, but also required them to learn and, importantly, display the identity of emergent scholar. We present our findings according to participants' roles and behaviors not as students transitioning to scholars, but as students-as-learners and scholars-as-learners.

While both programs trained students for careers as faculty members (exclusively in Business and predominantly in Higher Education), seven of the ten participants in Higher Education pursued administrative careers in Stage 3. All 18 Business students pursued faculty careers, and 17 secured tenure track positions. Our analysis is organized based on a comparison of the experiences with the dissertation and job search among future faculty with those of future administrators. For each milestone, we first provide an overview of participants' experiences and perceptions. Because participants described a commitment to the faculty career as normative in both departments, we focus on those experiences first and then turn to the experiences of students who pursued non- 
academic careers. For both populations, an emphasis on the parallel process of identity development through networked sociocultural learning helps us examine the ways in which community members support (or hinder) students' engagement in learning through knowledge enactment.

\section{The Dissertation}

The roles of student-as-learner and scholar-as-learner were both critical to student success in the dissertation process. There were two important ways in which participants cultivated their identities through the dissertation process. First, the dissertation served as a way for students to test their refined approaches to learning as they completed the process of knowledge creation and scholarly inquiry. Second, it was an opportunity for students to emerge as professionals in their own right. Importantly, however, students continued to rely on faculty members and peers to learn how to engage in this new process of knowledge enactment. We observed contradictory desires for both independence and support.

Fourteen participants discussed their efforts to move away from dependence on their dissertation chairs and committee members to a state of independence where they called the shots and felt comfortable doing so. One student commented, "I really do not want to be seen as a student any more. I want to be seen as a peer - well, at least a potential peer - based on my abilities." This struggle to assert independence in the midst of relying on their most trusted advisors and community members created tension for these students. Many participants spoke of resenting their need for support as they strove to emerge as scholars-as-learners. As one student stated,

I feel stuck. I can't seem to get past this 'needing help' stage and I hate it. I want to be on my own, doing my own thing, and proving to everyone and myself I can handle this. It's an awful feeling, really.

Twelve students spoke about daily writing goals and peer reviews as helpful in easing the stress of "not wanting to be a student, but still needing to be a student" as they neared the completion of their dissertations. These were practices that afforded the students a level of independence while also providing support from their developmental networks.

\section{Future faculty}

Future faculty saw the dissertation as a means of engaging in scholarly practices as they moved towards becoming fully participating members of the academic community. Students seeking faculty appointments upon graduation focused heavily on developing and demonstrating their scholarly identities. As one participant noted, "If I do not make a name for myself with my research, then I am dead in the water. Showing potential doesn't cut it. You have to show results to get a faculty appointment." In order to be accepted as bona fide scholars by existing community members, however, participants continued to depend on relationships with advisors, supervisors, and peers.

While students acknowledged their need for support, it conflicted with their need for autonomy. Internal struggles arose for many students as they sought to manage these relationships. As one student commented,

I'm not an idiot. I know how and why I was able to get the two publications I have in my pocket, which is helping me immensely on the job market. [My dissertation chair] is the expert in the field and he knows how to play the publication game. It is because of these two publications and who he is that helped me get the onsite job talks at these schools. While I am beyond appreciative, and I know how crazy this sounds, I need to start distancing myself. I need to show I can do this on my own. 
The students seeking faculty appointments wrestled with this tension of wanting to prove their worth as potential faculty members, while at the same time still relying on others to accomplish that goal. Participants responded to this tension by establishing scholarly goals in addition to their dissertation projects in order to assert control in the midst of the continued necessity of their student identities. Many discussed the need to publish from their dissertations, but also to quickly move on from that line of research. Fourteen participants talked about new projects, possible new collaborators they had met through the job search or professional conferences, and the need to be lead author in planned publications.

Students also had firm ideas about how to interact with their academic advisors and dissertation chairs. As an important step towards emerging as scholars, several participants discussed the need to transition from a student-advisor relationship to one characterized as a peer relationship. As one student noted,

I wonder if I will ever not feel like a student when interacting with [my advisor]. We have plans to continue collaborating once I start my [faculty] position, but I still feel as though I will always feel like a student when working with him. That's an issue I need to manage better, but I am not quite sure how to do that exactly.

Strategies students employed to that end included scheduling meetings in neutral locations other than their advisors' offices, volunteering to write first drafts of papers, and making contact with friendly reviewers to identify themselves as the point of contact on the paper. When their advisors enabled students to enact the behaviors of fully participating members of the academic community, students were more confident in their identities as credible scholars.

\section{Future administrators}

For the participants who did not want to become faculty members, the dissertation represented a different sort of challenge. They relied heavily on their student-as-learner identities to frame their dissertation studies in a way that was manageable, as they engaged in work of acquiring the less familiar, and less comfortable, role of scholar-as-learner, often uncertain of how they would enact that role in their administrative careers. One student talked about a shift in his ability to conceptualize his identity as a scholar as he completed the dissertation:

I've got to admit, I struggled. That was just hard. Lots of walks by myself to calm down. And that's when I realized - I used to joke that the dissertation is a big book report, but there is a transition there. It becomes a dissertation, it becomes real, it becomes research.

Despite these challenging transitions, like the future faculty members, students with administrative career goals spoke positively about the expectations placed on them by the faculty and the high standards of academic excellence in their programs. One student recalled,

That process is completely satisfying and really enjoyable and exhilarating. And to share that with others is amazing. ... Just being in that space and that moment, it was fun. I'm so thankful that I did it, and had the people and support around me.

The dissertation was a critical turning point for administratively focused students as they engaged in discernment about their career goals. Unlike the certainty demonstrated by those who identified as future faculty, six of the seven participants in this group indicated that they had not been sure whether they would pursue academic or administrative appointments until they completed Stage 3. On the one hand, the dissertation provided a realistic preview of what it would be like to engage in faculty work, which influenced these students' decisions to invest in administrative careers. On the other hand, however, it was not simply a deterrent. Their career goals did not separate them from their peers in terms of their interest in being trained rigorously and making 
meaningful scholarly contributions through their original research. One student recalled how her dissertation affected her career goals,

I think it was all coming full-circle for me as I was finishing up my dissertation work.... In reviewing the research I was doing and the model I was creating, I could see the opportunity for a greater effect coming through an administrative side where I can work with the students and faculty. I hate to think that we're not having an effect.

The opportunity to engage in meaningful scholarship equipped these students with a strong sense of professional expertise and clarity about how they could best contribute to practice.

Part of the distinction in the relationship between the dissertation process and the professional identities of future faculty members and those of future administrators seemed to be based on access to practices similar to those expected in one's profession of choice. Though their dissertations were meaningful, they did not mirror the type of research these students would be expected to do in administrative careers. Those students, however, seemed to have more of a clean break in their role transitions than their peers who pursued faculty appointments when they transitioned out of their academic programs. We explore these differences further by discussing the second major milestone of Stage 3, the job search.

\section{The Job Search}

Across career goals, study participants discussed two primary challenges related to the job search. The first was simply finding employment. The second was renegotiating personal and professional relationships and managing expectations during the transition from student to scholar. Study participants began teasing out the roles that advanced students, support staff, and faculty members played in their entrance into the job market. Participants described the ways in which their developmental relationships within the academic community provided the support needed to achieve their goals as students while simultaneously preparing them for "life beyond the program," as one student described it, which began by obtaining an academic or administrative position.

When discussing the job search process, students reintroduced the importance of another component of their developmental networks - their relationships outside the academic community. Many of the students had partners and families to consider as important factors in the job search. Participants also described concerns about asserting their decision-making autonomy to their advisors and program faculty, many of whom students believed expected them to obtain faculty appointments at competitive programs, while remaining dependent on them for training and support. As one student noted,

I have a family, a life outside of this, and that plays an important role. I will not sacrifice my happiness or [my spouse's] happiness to please my department or [dissertation chair]. They've made it clear what they want, but now it's my turn to really think about what is in my best interest personally and professionally - for the first time in five years.

Although they valued their departments, nearly all participants noted that departmental goals and faculty expectations were not the primary driver of their job search efforts, and that they were making deliberate efforts to discern what was right for them personally. Friends and family members began to rise in importance in students' developmental networks. This was true for all participants, regardless of career goals. As another student commented, "For the first time in a long time, I see the light at the end of the tunnel and look forward to reengaging in relationships that took a back seat nearly five years." In addition to these commonalities, the job search was also the program milestone through which the parallel processes of identity development diverged for these two groups of students. 


\section{Future faculty}

Applying and preparing for a faculty appointment was a job in and of itself that required immense physical, emotional, and mental effort, according to some participants. Developmental relationships helped those pursuing faculty careers to learn the formal and informal skills required to manage the academic job market. Students described the job search process as exploring possible positions, practicing job talks, and identifying possible mentors. One student said of the way her faculty mentors and supported her job talk preparation, "I reframed my talk and it was the best thing - not because $I$ did it, but because it worked. I started getting offers. And it was just invaluable, that feedback." Another student noted the dual purposes his mentors served in his job search:

During the job talk, I realized I was working with two groups of individuals. The content experts were making sure I was solid on my methodological and theoretical frameworks, which was the primary goal.... On the job market, however, I need to be a storyteller and brand myself so some of the departmental faculty that attended pushed me in this way.

In Business, there was a cultural norm that helped ease this daunting task in a practical way. Administrative support staff members would prepare students' job packets on their behalf. Helping reduce some of the stress associated with the job search allowed students to focus on more pressing matters such as perfecting the job talk, networking skills, and responses to possible interview questions.

During the academic job search, students reported feeling that they had to "act like an academic." That is where students expressed the need for the most support from their mentors. One student noted,

It's now time to own it. I need to show that I can do it, and believe in myself that I can do it. I've practiced my job talk to the point I can't even stand hearing it myself, but I know I am prepared. I just need to get others to see my worth and the value I bring to the table.

Participants seemed to realize that their student identities no longer sufficed. They now had to show that the past four or five years prepared them to be successful scholars as they sought to fully join the scholarly and disciplinary communities. While those extending the offers had expressed the ability to see the students as scholars, the students often doubted their own abilities to make the transition. A participant who had recently begun his academic appointment noted, "It hasn't sunk in yet ... I see my name on the door, but I am still so connected to my advisor that I don't see myself as self-sufficient yet." Participants who sought faculty positions expressed uneasiness about transitioning to their roles as early-career academics, and relied on their developmental networks to support their transitions during these times.

\section{Future administrators}

Participants who were not seeking academic appointments described their job search experiences differently from those who sought to become faculty members. The notion of making a name for oneself was a concern in a different way. For these participants, there was more of a reliance on practical skills and prior professional networks than a need to present a newly emerged self as independent scholar. The shift towards (or back to) their professional identities required a redefinition of their relationships within their developmental networks. They were being recruited and interviewed by fellow practitioners who did not view the scholarly identity the same way that academic search committees within the disciplines would. They were engaged in a search process that was not conducted at the disciplinary association meetings or managed by academic search committees, nor were they dependent on the traditional start dates based on the academic 
calendar or negotiating such details as course loads and tenure clocks. One future administrator recalled,

Professionally, I don't remember anyone helping me, and I can't remember who I talked to about the job. I never networked and said, "Hey, I'm looking for a job." And I was the graduate student representative for [a professional organization]! That's access to the top people in the field! I think it's lack of confidence or not knowing if it was appropriate [but] I never tapped into that.

When discussing their experiences, these students recalled being more hesitant about how to proceed and less sure of who to call upon for help. They seemed to be disappointed in this aspect of their experiences as they sought to navigate the transition from student-as-learner to scholar-aslearner in ways that were not modeled, and perhaps not supported, by their program faculty.

All seven of the participants who chose administrative careers described pressure from their faculty and the more general culture of their programs to choose academic work over administrative work. A student said, "Anything that was contrary to wanting a faculty position seemed foreign and, therefore, unacceptable. So I put pressure on myself to conform." These students described complex feelings related to being thought of as "less-than" if they did not obtain, or worse, pursue a faculty position in Stage 3. Regarding the decision about which career path to choose, participants described very intentional, honest, sometimes painful periods of reflection. One person felt so pressured to pursue the faculty track that he had to disassociate from his department upon completion of Stage 3. He recalled,

I'm leaving the program being told that I should be a faculty member. I didn't know if that's what I wanted so I stopped all things academic. I, honestly, I just stopped it. I cut ties. I needed to branch away from what everybody was telling me I should do and really think about it, 'Is this how I want my life to progress? Is this what I want to do with my life? Where will I fit in the best? What will make me happy?' I realized I wanted to go back into administration. I don't want to be a faculty member.

He concluded that he shouldn't expect support from his faculty mentors in his job search because he had cut ties with them. He asserted, "I wanted it to be my life now. Instead of my life as a graduate student, I wanted it to be my life as a professional."

Students with administrative career goals seemed eager to assume their professional roles. The greatest challenge they faced was a perceived deficit of support, guidance, relationships, and knowledge of practices similar to what they would experience as administrators as they sought to become actively engaged in non-academic community practices. They were uncertain of how to obtain administrative appointments or how to rely on their networks during the transition from student to professional. Differing career goals coupled with limited opportunities for future administrators to engage in the relevant professional practices resulted in greater uncertainty and feelings of peripheral membership in their academic programs.

\section{Conclusion}

Our goal for embarking on this longitudinal study was to better understand the doctoral student experience in two social science disciplines by exploring the parallel process of identity development (Baker \& Pifer, 2011). We grounded our work using a theoretical framework that brings together developmental networks and the sociocultural conception of learning (Baker \& Lattuca, 2010). In this article, we addressed the paucity of research about Stage 3 and further refined the notion of parallel identity development processes that is triggered by knowledge enactment as related to the dissertation and job search. The descriptor knowledge enactment is particularly salient for Stage 3, as students not only enact their new knowledge to successfully navigate the dis- 
sertation and job search experiences but also learn how to be scholars and members of their disciplinary and professional communities.

\section{Significance}

This study generated several findings that contribute to knowledge about Stage 3 of doctoral education. First, this research builds on the notion of the 3-stage model as a foundation for research about the doctoral student experience and establishes Stage 3 as a time of knowledge enactment. The parallel process of identity development that we first documented as a characteristic of Stage 2 (though we suspect that it begins prior to that) manifests itself in a unique way in Stage 3 as doctoral students attempt to manage the sometimes contradictory process of enacting the studentas-learner identity while simultaneously enacting the scholar-as-learner identity. Spanning the student role and the scholar role, learning is fundamental to student success during this process, specifically the ways in which students' approaches to learning evolve as they engaged in the dissertation and the job search.

Second, in support of Hall (1968), study results suggest that completing the dissertation and the job search triggers students' identity development. Relying on the notion of a networked sociocultural learner, the dissertation and job search facilitated students' movement beyond the periphery towards more central places in the communities of practice they sought to enter as future faculty members and administrators (Lave \& Wenger, 1991). For those interested in securing faculty positions, departmental practices such as job talks, preparing job packets, and honing research skills helped students "look like" faculty as they entered the academic labor market. The knowledge gained from these practices helped students to display the necessary skills within their respective fields, and thus be accepted as emergent members of those communities. These students were continuing to develop as they prepared for their new roles by engaging in the practices of the field in the larger academic community. They were learning how to gain legitimacy beyond the academic programs within which they were enrolled.

For the future administrators, this process was more challenging, given the lack of similar practices supported by the academic program, which hindered their ability to enact professional behavior as prospective administrators. This group of students reported feeling undervalued by their faculty members and the cultures of their programs in their decisions to pursue nonacademic careers, which resulted in a different sort of stress during Stage 3 and fewer tangible and psychological sources of support than those experienced by future faculty members. Faculty members are not in a particularly good position to support these students in the same ways they can support future faculty. Lack of relevant experiences during their doctoral training limited these students' ability to engage in community practices or to build and operationalize effective networks during their job searches and transitions out of the student role, which hindered their knowledge enactment processes and development as emergent professionals. The sociocultural lens helps us understand the meaning that participants attributed to community, one's role in that community, and the practices that make up that community as they sought to earn legitimacy and move towards a central position.

Third, we sought to further refine and test the parallel process of identity development we first identified as part of the Stage 2 doctoral student experience (Baker \& Pifer, 2011). The integrative framework provided the foundation needed to understand the role of relationships during the dissertation and job search experiences, critical practices of the doctoral experience that are unique to Stage 3. Understanding how students successfully transition through these Stage 3 milestones into the early stages of their careers sheds light on persistence in the profession (faculty and administrative) and the ways in which doctoral programs facilitate or hinder professional identity development and learning strategies for emergent professionals across diverse career goals. Making these connections adds a missing piece to the stage model framework by adding to 
knowledge of how students move through knowledge consumption (Stage 1), knowledge creation (Stage 2) and knowledge enactment (Stage 3) towards program completion and employment.

\section{Implications for Research}

While the findings from this research have contributed to our understanding of doctoral education, they also illuminate several areas about which future research would be helpful. First, additional research is needed to explore the parallel identity development process in other disciplines

and doctoral education models. For example, in the sciences it is common for students to work in labs, some of which may include only one or two other researchers. While these students are introduced to community practices early in their academic experience, they may struggle to gain the support and knowledge development needed due to limited engagement with community members. Additionally, the emergence of different types of doctoral programs such as online, hybrid, accelerated, professional, and executive programs, requires additional testing and refinement of the parallel identity development process.

Applying this notion globally, future studies might explore this process in programs that differ structurally from the US model. Many doctoral programs begin with original research, without the foundational coursework prominent in Stage 1 of the traditional American model. This difference raises questions about how students' learning evolves and how their identities develop, as well as what role developmental networks and key experiences play in those processes.

Finally, the notion of community, critical for understanding the networked sociocultural learner, may be a fruitful area for further exploration. Research suggests that engagement in community practices and creating a network of social support are critical to doctoral student success (Jairam \& Kahl, 2012). Differing program structures and disciplines may define community and its corresponding practices, members, and rights to membership in different ways. Understanding the role of community has the potential to shed additional light on the doctoral student experience, identity development processes, and strategies for persistence.

\section{Implications for Practice}

We suggest several opportunities to improve the practice of doctoral education based on our findings. First, programs and departments might emphasize structured, formal support for students transitioning from the student-as-learner role to that of scholar-as-learner such as practice job talks, workshops about the logistics of the job search, or guided opportunities to write for publication. While this may already be common practice in some disciplines and institutions, our findings suggest that these practical tools or similar discipline-specific strategies, facilitated by established scholars, may be of great support to students transitioning through Stage 3.

Faculty members may benefit from discussing the parallel identity development process as it relates to advising and training in the official business of the department and the discipline, based on a more clear understanding of the challenges of the dissertation and the job search. One of the most important resources faculty members can offer to their students during this stage is their social or academic capital, to make introductions and recommend students for positions. We encourage faculty members to think deliberately about the student experience in Stage 3, and their ability to actively support students during this time.

Another important opportunity is student selection based on fit with program goals and culture, as well as having a clear sense of departmental culture and faculty mentoring capabilities related to diverse career goals. As the academic job market continues to change, and as other forces such as the shift towards a global knowledge economy continue to affect career goals, training requirements, and employment opportunities, academic programs may be well served to become more effective in cultivating administrators, educators, researchers, and other types of professionals 
beyond the traditional but more narrowly construed concept of the scholar, which may not adequately address the needs and future roles of today's doctoral learners.

Finally, we encourage students to develop and enact a sense of personal agency. Doctoral education is in many ways an independent process and the student must be equipped to take responsibility for her or his success. This may be achieved through steps such as establishing personal goals, taking ownership of meeting requirements, obtaining clarity about expectations, and seeking help when needed. If doctoral students and their teams of developers and supporters can communicate openly about the challenges of Stage 3, it may reduce the negative effects of these challenges substantially.

Although earning the doctorate is in many ways a lonely journey, there is a broad developmental network available to support students. Such support is most likely to be offered when faculty members, family members and friends, administrators, and peers understand what students are experiencing and feel equipped and welcome to offer support. Stronger dissertations, higher completion rates, more successful job searches, and better trained graduates are, after all, benefits for students, programs, disciplines, institutions, professions, and the range of other stakeholders in doctoral education. We offer these suggestions to help make the high-stakes process of doctoral education equally prominent in its rewards.

\section{Acknowledgements}

We gratefully thank Lisa Lattuca, Melissa McDaniels, and our anonymous reviewers for their advice as we developed the ideas presented in this manuscript. A prior version of this paper was presented at the Association for the Study of Higher Education in Las Vegas, Nevada (November, 2012). This research was supported by a grant from the Hewlett-Mellon Fund for Faculty Development at Albion College in Albion, Michigan.

\section{References}

Anastas, J. W. (2006). Employment opportunities in social work education: A study of jobs for doctoral candidates. Journal of Social Work Education, 42(2), 195-209.

Anderson, B., Cutright, M., \& Anderson. S. (2013). Academic involvement in doctoral education: Predictive value of faculty mentorship and intellectual community on doctoral education outcomes. International Journal of Doctoral Studies, 8, 195-201. Retrieved from http://ijds.org/Volume8/IJDSv8p195201Anderson0405.pdf

Applegate, B. K., Cable, C. R., \& Sitren, A. H. (2009). Academia's most wanted: The characteristics of desirable academic job candidates in Criminology and Criminal Justice. Journal of Criminal Justice Education, 20(1), 20-39.

Austin, A. E. (2002). Preparing the next generation of faculty: Graduate school as socialization to the academic career. Journal of Higher Education, 73(1), 94-122.

Austin, A. E., \& McDaniels, M. (2006). Preparing the professoriate of the future: Graduate student socialization for faculty roles. In J. C. Smart (Ed.), Higher education: Handbook of theory and research, XXI, 397-456.

Baxter Magolda, M. B. (2001). Making their own way: Narratives for transforming higher education to promote self-development. Sterling, VA: Stylus.

Baker, V. L., \& Lattuca, L. R. (2010). Developmental networks and learning: An interdisciplinary perspective on faculty identity development during doctoral study. Studies in Higher Education, 35(7), 807827.

Baker, V. L., \& Pifer, M. J. (2011). The role of relationships in the transition from doctoral student to independent scholar. Studies in Continuing Education, 33(1), 5-17. 
Baker, V. L., Pifer, M. J., \& Flemion, B. (July/August, 2013). Process challenges and learning-based interactions in stage 2 of doctoral education: Implications from two applied social science fields. Journal of Higher Education, 84(4), 449-476.

Baker Sweitzer, V. (2007). Professional identity development among business doctoral students: A social networks perspective. (eTD unpublished dissertation).

Barnes, S. L. (2007). On the market: Strategies for a successful academic job search. Boulder, CO: Lynne Rienner.

Caplow, T., \& McGee, R. J. (1958/2001). The academic marketplace. New York, NY: Basic Books.

Chickering, A., \& Reisser, L. (1993). The seven vectors: An overview. Education and Identity: The JosseyBass Higher and Adult Education Series (pp. 43-52). San Francisco, CA: Jossey-Bass.

Council of Graduate Schools. (1990). The doctor of philosophy degree: A policy statement. Washington, DC: Council of Graduate Schools.

Eisenhardt, K. M. (1989). Building theories from case study research. The Academy of Management Review, 14(4), 532-550.

Gardner, S. K. (2007). "I heard it through the grapevine": Doctoral student socialization in Chemistry and History. Higher Education, 54, 723-740.

Gardner, S. K. (2008). "What's too much and what's too little?" The process of becoming an independent researcher in doctoral education. Journal of Higher Education, 79(3), 326- 350.

Geiger, R. (1997). Doctoral education: The short-term vs. long-term crisis. The Review of Higher Education, 20(3), 239-251.

Golde, C. M. (1998). Beginning graduate school: Explaining first-year doctoral attrition. In M. S. Anderson (Ed.), New directions for higher education, 55-64.

Golde, C. M., \& Dore, T. M. (2001). At cross purposes: What the experiences of today's doctoral students reveal about doctoral education. Philadelphia, PA: Pew Charitable Trusts.

Grover, V. (2007). Successfully navigating the stages of doctoral study. International Journal of Doctoral Studies, 2, 9-21. Retrieved from http://www.ijds.org/Volume2/IJDSv2p009-021Grover21.pdf

Hall, D. T. (1968). Identity changes during the transition from student to professor. School Review, 76, 445-469.

Hargens, L. L. (2011). Academic labor market at assistant professors employment outcomes. Research in Higher Education, 53(3), 311-324. doi: 10.1007/s11162-011-9228-1

Isaac, P. D., Quinlan, S. V., \& Walker, M. M. (1992). Faculty perceptions of the doctoral dissertation. The Journal of Higher Education, 63(3), 241-268.

Jairam, D., \& Kahl, D. H., Jr. (2012). Navigating the doctoral experience: The role of social support in successful degree completion. International Journal of Doctoral Studies, 7, 311-329. Retrieved from http://ijds.org/Volume7/IJDSv7p311-329Jairam0369.pdf

Jazvak-Martek, M. (2009). Oscillating role identities: The academic experiences of education doctoral students. Innovations in Education and Teaching International, 46(3), 253-264.

Kiley M. (2009). Identifying threshold concepts and proposing strategies to support doctoral candidates. Innovations in Education and Teaching International, 46(3), 293-304. doi: $10.1080 / 14703290903069001$

Krathwohl, D. R., \& Smith, N. L. (2005). How to prepare a dissertation proposal: Suggestions for students in education \& the social and behavioral sciences. Syracuse, New York: Syracuse University Press.

Lave, J., \& Wenger, E. (1991). Situated learning: Legitimate peripheral participation. New York, NY: Cambridge University Press. 
Lehker, T., \& Furlong, J. S. (2006). Career services for graduate and professional students. New Directions for Student Services, 115, 73-83.

Lipschutz, S. S. (2006). Enhancing success in doctoral education: From policy to practice. New Directions for Institutional Research, 80, 69-80.

Lovitts, B. E. (2005). Being a good course-taker is not enough: A theoretical perspective on the transition to independent researcher. Studies in Higher Education, 30(2), 137-154.

Lovitts, B. E. (2008). The transition to independent research: Who makes it, who doesn't, and why. Journal of Higher Education, 79(3), 296-325.

MacQueen, K. M., McLellan, E., Kay, K., \& Milstein, B. (1998). Codebook development for team based qualitative analysis. Cultural Anthropology Methods, 10(2), 31-36.

Merriam, S. B. (2002). Introduction to qualitative research. In S. B. Merriam and Associates (Eds.), Qualitative research in practice: Examples for discussion and analysis (pp. 3-18). San Francisco, CA: Jossey-Bass.

Miles, M. B., \& Huberman, A. M. (1994). An expanded sourcebook: Qualitative data analysis. Thousand Oaks, CA: Sage.

Patton, M. Q. (2002). Qualitative research and evaluation methods (3rd ed.). Thousand Oaks, CA: Sage.

Pearson, M. (1999). The changing environment for doctoral education in Australia: implications for quality management, improvement and innovation. Higher Education Research \& Development, 18(3), 269287.

Roberts, C. M. (2010). The dissertation journey: A practical and comprehensive guide to planning, writing, and defending your dissertation. Thousand Oaks, CA: Sage.

Smeets,V., Warzynski, F., \& Coupé, T. (2006). Does the academic labor market initially allocate new graduates efficiently? Journal of Economic Perspectives, 20(3), 161-172.

Tinto, V. (1993). Leaving college: Rethinking the causes and cures of student attrition. Chicago, IL: University of Chicago Press.

U.S. News and World Report. (2011). Retrieved from www.usnews.com

Weidman, J. C., Twale, D. J., \& Stein, E. L. (2001). Socialization of graduate and professional students in higher education: A perilous passage. ASHE-ERIC Higher Education Report 28(3), Washington, DC: Association for the Study of Higher Education.

Yerkes, M., van de Schoot, R., \& Sonneveld, H. (2012). Who are the job seekers? Explaining unemployment among doctoral recipients. International Journal of Doctoral Studies, 7, 153-66. 


\section{Biographies}

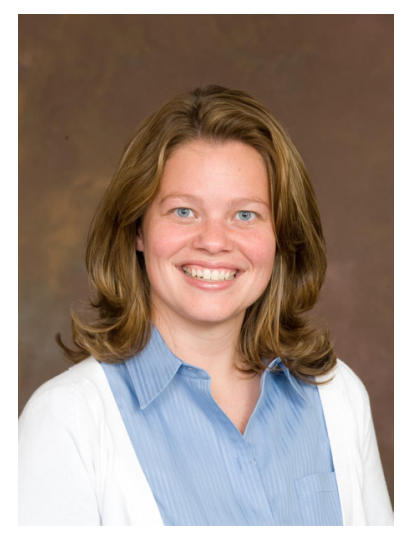

Vicki L. Baker is an Associate Professor of Economics \& Management at Albion College, where she teaches courses in management, leadership and organizational behavior. Her scholarly interests include developmental networks, identity development of doctoral students, and faculty development in liberal arts colleges.

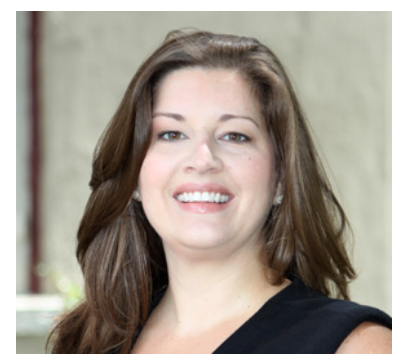

Meghan J. Pifer is Assistant Professor of Higher Education at Widener University, where she teaches courses such as faculty professional development, teaching and learning in higher education, and organization and governance in higher education. Her scholarly interests include faculty work and careers, graduate education and preparation for the professoriate, and equity and access in the academy. 